\title{
ANALISIS KORPUS BAHASA INGGRIS SEBAGAI MASUKAN BAGI KORPUS BAHASA INDONESIA
}

\author{
Irpan Apandi Batubara ${ }^{1}$ \\ Wariyati $^{2}$ \\ Universitas Muslim Nusantara Al Washliyah \\ Jl. Garu II No. 93, Medan \\ irpan.batubara@yahoo.co.id ${ }^{1}$ \\ nengyaticpkro12@yahoo.com ${ }^{2}$
}

\begin{abstract}
Abstrak
Bahasa Inggris sebagai bahasa internasional meyerap tidak sedikit kosakata dari bahasa asing termasuk dari Bahasa Indonesia. Analisis reflektif terhadap korpus Bahasa Inggris penting dilakukan dalam rangka membantu menginternasionalkan Bahasa Indonesia. Penelitian dilakukan dengan analisis kualitatif secara daring maupun luring terhadap kamu monolingual bahasa Inggris. Terdapat 41 kata dari Bahasa Indonesia yang diserap ke dalam Kamus bahasa Inggris. Hal ini berarti para praktisi linguistik perlu berperan lebih aktif.
\end{abstract}

Kata Kunci: korpus bahasa inggris, analisis reflekstif, korpus bahasa indonesia

\begin{abstract}
English as an international language absorbs not a few vocabulary from foreign languages including from Bahasa Indonesia. A reflective analysis of the English corpus is important in order to help internationalize the Indonesian language. Research is done by qualitative analysis online or offline against you language monolingual. There are 41 words from Indonesian that are absorbed into the English dictionary. This means that linguistic practitioners need to be more active.
\end{abstract}

Keywords: english corps, reflective analysis, indonesian corps

\section{Pendahuluan}

Pada tanggal 26-29 Juli 2016

$\begin{array}{lcr}\text { Badan } & \text { Pengembangan } & \text { dan } \\ \text { Pembinaan } & \text { Bahasa } & \text { pusat }\end{array}$ menyelenggarakan Seminar

Leksikografi Indonesia dengan

mengangkat tema "Tantangan

Leksikografis Bahasa-bahasa Daerah

di Indonesia". Perkembangan teknologi menjadi tantangan tersendiri dalam meregistrasi dan mendokumentasi kekayaan bahasa nusantara. Selanjutnya tantangan lainnya adalah terkait sikap bahasa para penutur dengan latar belakang era digital seperti sekarang ini. Dokumentasi bahasa digital dalam bentuk kamus elektronik bahasa asing 
berkembang sangat pesat dan itu relevan dengan kondisi pengguna bahasa di Indonesia yang sudah melek teknologi.

Kamus elektronik saat ini menjadi sangat vital dalam pembelajaran bahasa. Hal ini sejalan dengan era digital yang memungkinkan para pembelajar bahasa dapat memperoleh informasi tanpa harus membawa kamus tebal kemana-mana. Ada kamus elektronik yang dapat diintegrasikan dengan perangkat telepon genggam dimana para pembelajar bahasa dapat mengunggahnya dan memasangkannya. Bukan hanya itu, kamus elektronik juga banyak yang tersedia untuk dipasang di perangkat komputer sehingga para pembelajar bahasa dapat langsung membuka kamus elektronik jenis ini sambil mereka bekerja di komputer yang sama (Atkins and Rundell, 2008: 10).

Kamus sebagai alat bantu pembelajaran bahasa dewasa ini bukan hanya sekedar untuk menemukan padanan kata, tetapi juga untuk dapat menggunakan kata tersebut dengan konteks yang tepat. Kerap sekali ditemukan kata-kata yang memiliki padanan dalam bahasa
Indonesia, tapi tidak dalam bahasa inggris atau sebaliknya. Kamus elektronik yang dapat dijumpai saat ini dilengkapi dengan beberapa fitur yang memungkinkan kamus bukanlah lagi sekedar sumber arti kata tetapi juga sumber referensi.

Selanjutnya, ekspansi bahasa Indonesia seperti yang digalakkan pada Kongres Bahasa 2014 terasa seperti bertepuk sebelah tangan bila Praktisi Leksikografi local tidak melihat bahasa mereka dari sisi penutur bahasa asing.

Untuk itulah penelitian ini penting dilakukan agar rancangan leksikografi Indonesia relevan dengan perkembangan leksikografi global.

Pada akhirnya, untuk mewujudkan cita-cita menginternasionalkan Bahasa Indonesia, Praktisi bahasa perlu melakukan analisis reflektif. Mengapa batik yang menjadi pusat perhatian? Jawabannya akan dibahas dalam temuan penelitian. Analisis korpus menjadi penting dalam menginternasionalkan bahasa Indonesia sebab Korpus adalah 
sumber belajar bahasa yang terpenting.

\section{Metode}

Penelitian ini akan menggunakan analisis kualitatif. Proses analisis direpresentasikan sebagai tiga fase utama: persiapan, pengorganisasian dan pelaporan dilakukan. Selanjutnya akan dilakukan analisis kualitatif dengan cara multifase di mana akan dilakukan analisis offline dan analisis daring berbasis internet.

\section{Hasil dan Pembahasan}

Analisis dilakukan secara kualitatif dengan obyek penelitian adalah kamus monolingual (InggrisInggris) Bahasa Inggris yang terdapat di perpustakaan Universitas Negeri Medan, Universitas Sumatera Utara, dan Universitas Muslim Nusantara. Ketersediaan Kamus tersebut tergambar seperti table berikut:

Tabel 1. Daftar lokasi dan Kamus Monolingual Yang Tersedia

\begin{tabular}{|l|l|l|}
\hline $\begin{array}{l}\text { No } \\
\cdot\end{array}$ & Lokasi & $\begin{array}{l}\text { Kamus } \\
\text { Tersedia }\end{array}$ \\
\hline 1 & $\begin{array}{l}\text { Digital } \\
\text { Library }\end{array}$ & $\begin{array}{r}\text { 1. Longman } \\
\text { Dictionary }\end{array}$ \\
\hline
\end{tabular}

\begin{tabular}{|c|c|c|}
\hline & $\begin{array}{l}\text { Universitas } \\
\text { Negeri } \\
\text { Medan }\end{array}$ & $\begin{array}{l}\text { 2. Oxford } \\
\text { Advanced } \\
\text { Dictionary } \\
\text { 3. The hold } \\
\text { intermediat } \\
\text { e dictionary } \\
\text { of } \\
\text { American } \\
\text { English }\end{array}$ \\
\hline 2 & $\begin{array}{l}\text { Perpustakaa } \\
\mathrm{n} \\
\text { Universitas } \\
\text { Muslim } \\
\text { Nusantara } \\
\text { Al } \\
\text { Washliyah }\end{array}$ & $\begin{array}{l}\text { 1. Oxford } \\
\text { Advanced } \\
\text { English } \\
\text { Dictionary }\end{array}$ \\
\hline 3 & $\begin{array}{l}\text { Perpustakaa } \\
\mathrm{n} \\
\text { Universitas } \\
\text { Sumatera } \\
\text { Utara }\end{array}$ & $\begin{array}{l}\text { 1.Oxford } \\
\text { Advanced } \\
\text { English } \\
\text { Dictionary }\end{array}$ \\
\hline
\end{tabular}

Selain kamus cetak di atas, analisis juga dilakukan terhadap kamus online, yaitu collinsdictionary.com.

Frasa Ilustratif tentang Indonesia yang ditemukan pada keseluruhan kamus baik cetak maupun online direpresentasikan dalam table berikut: 


\section{Tabel 2. Frasa Ilustratif Kata Serapan Dari Bahasa Indonesia dalam Korpus}

\section{Bahasa Inggris}

\begin{tabular}{|c|c|c|c|}
\hline No. & Entri & Frasa Ilustratif & Domain \\
\hline 1. & Indonesia & 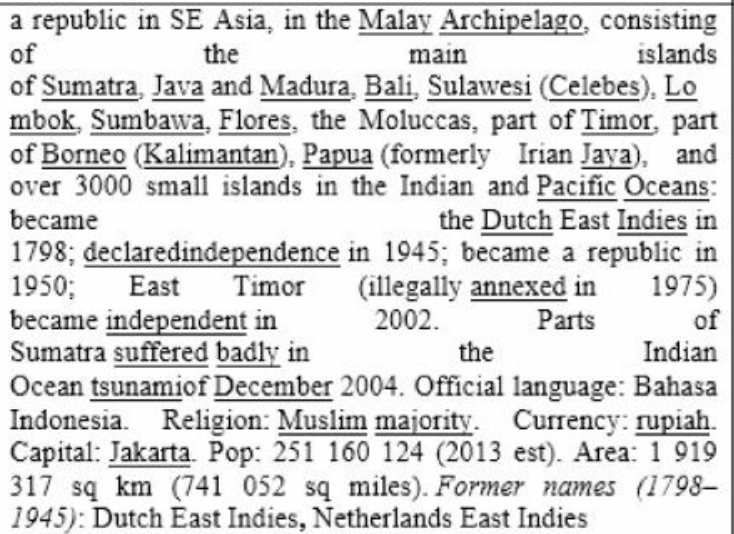 & Geografi \\
\hline 2. & Sumatra & 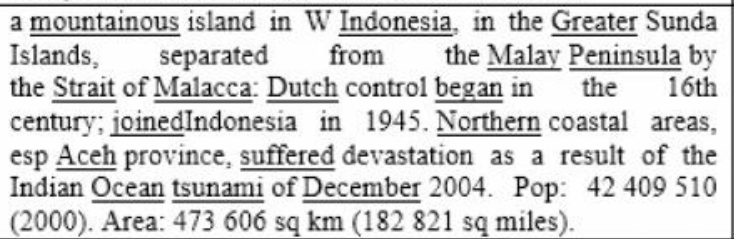 & Geografi \\
\hline 3. & Jakarta & $\begin{array}{l}\text { the capital of Indonesia, in N West Java: founded in } 1619 \\
\text { and ruled by the Dutch until } 1945 \text {; the chief trading centre of } \\
\text { the East in the } 17 \text { th century; University of Indonesia (1947). } \\
\text { Pop: } 8347083 \quad(2000) \text {. Former name (until } \\
\text { 1949): Batavia. Former spelling. Djakarta }\end{array}$ & Geografi \\
\hline 4. & Bali & $\begin{array}{l}\text { an island in Indonesia, east of Java: mountainous, rising over } \\
3000 \mathrm{~m} \text { (10 000 ft). Capital: Denpasar. Pop: } \frac{3151162}{3150} \text {. Area: } 5558 \mathrm{sq} \mathrm{km}(2146 \mathrm{sq} \text { miles) }\end{array}$ & Geografi \\
\hline 5. & Nasi Goreng & $\begin{array}{l}\text { a dish, originating in Malaysia, consisting of rice fried with } \\
\text { a selection of other ingredients }\end{array}$ & Makanan \\
\hline 6. & Medan & $\begin{array}{l}\text { a city in Indonesia, in NE Sumatra: seat of the University of } \\
\text { North Sumatra (1952) and the Indonesian Islam University } \\
\text { (1952). Pop: } 1904273(2000)\end{array}$ & Geografi \\
\hline 7. & Padang & (in Malaysia) a playing field & Geografi \\
\hline 8. & Batik1 & $\begin{array}{l}\text { 1. a process of printing fabric in which parts not to } \\
\text { be dyed are covered by wax } \\
\text { 2. fabric printed in this way }\end{array}$ & Linguistik \\
\hline 9. & Batik2 & $\begin{array}{l}\text { (as modifier) } \\
\Rightarrow \text { a batik shirt }\end{array}$ & Linguistik \\
\hline 10. & Batik3 & $\begin{array}{l}\text { A batik is a cloth which has been printed with a batik } \\
\text { design. } \\
\Rightarrow \text {... a four-poster bed decorated with local batiks. } \\
\Rightarrow \text {...batik from Balt. }\end{array}$ & Fashion \\
\hline 11. & Orang & short for orang-utan & Biology \\
\hline 12. & Orang-utan & $\begin{array}{l}\text { An orang-utan is an ape with long reddish hair that comes } \\
\text { from Borneo and Sumatra. }\end{array}$ & Biology \\
\hline 13. & Yogyakarta & $\begin{array}{l}\text { a city in S Indonesia, in central Java: seat of government of } \\
\text { Indonesia (1946-49); university }(1949) \text {. Pop: } 396711 \\
(2000) \text {. Former spellings: Jogjakarta, Jokjakarta }\end{array}$ & Geografi \\
\hline
\end{tabular}




\begin{tabular}{|c|c|c|c|}
\hline 14. & Surabaya & $\begin{array}{l}\text { a port in Indonesia, on E Java on the Surabaya Strait: the } \\
\text { country's second port and chiefnaval base; university (1954); } \\
\text { fishing and ship-building industries; oil refinery. Pop: } \\
2599796(2000) \text {. Former spelling: Soerabaja }\end{array}$ & Geografi \\
\hline 15. & Bandung & a city in Indonesia, in SW Java. Pop: $2136260(2000)$ & Geografi \\
\hline 16. & Jambi & $\begin{array}{l}\text { a port in W Indonesia, in SE Sumatra on the Hari River. } \\
\text { Pop: } 417507(2000) \text {. Former spelling: Djambi. Also } \\
\text { called: Telanaipura. }\end{array}$ & Geografi \\
\hline 17. & Palembang & $\begin{array}{l}\text { a port in W Indonesia, in } \\
\text { S Sumatra; } \text { oil refineries; university (1955). Pop: } 1451419 \\
(2000)\end{array}$ & Geografi \\
\hline 18. & Semarang & $\begin{array}{l}\text { a port in S Indonesia, in N Java on the Java Sea. Pop: } \\
1348803(2000)\end{array}$ & Geografi \\
\hline 19. & $\begin{array}{l}\text { Bandar } \\
\text { Lampung }\end{array}$ & $\begin{array}{l}\text { a port in Indonesia, in S Sumatra on the Sunda Strait; } \\
\text { formed by merging the cities } \\
\text { of Taniungkarang and Telukbetung, and sometimes still } \\
\text { referred to as Tanjungkarang-Telukbetung. Pop: } 742749 \\
(2000)\end{array}$ & Geografi \\
\hline 20. & Madura & $\begin{array}{l}\text { an island in Indonesia, off the } \\
\mathrm{NE} \text { coast of Java: extensive forests and } \frac{\text { saline springs. }}{\text { Capital: Pamekasan. Area: } 5472 \mathrm{sq}} \mathrm{km}(2113 \text { sq miles }) \\
\text { (2) }\end{array}$ & Geografi \\
\hline 21. & Sate/Satay & $\begin{array}{l}\text { Satay is pieces of meat cooked on thin sticks and served } \\
\text { with a peanut sauce. } \\
\Rightarrow \text {...chicken satay. }\end{array}$ & Makanan \\
\hline 22. & Sulawesi & $\begin{array}{l}\text { an island in E Indonesia: mountainous and forested, } \\
\text { with volcanoes and hot springs. Pop: } 14946488(2000) \text {. } \\
\text { Area (including adjacent islands): } 229108 \mathrm{sq} \mathrm{km} \mathrm{(} 88440 \mathrm{sq} \\
\text { miles). Also called: Celebes }\end{array}$ & Geografi \\
\hline 23. & Flores & $\begin{array}{l}\text { an island in Indonesia, one of the Lesser Sunda Islands, } \\
\text { between the Flores Sea and the Savu Sea: mountainous, } \\
\text { with active volcanoes and unexplored forests. Chief town: } \\
\text { Ende. Area: } 17150 \mathrm{sq} \mathrm{km} \text { (6622 sq miles) }\end{array}$ & Geografi \\
\hline 24. & Komodo & after Komodo Island, Indonesia & Geografi \\
\hline 25. & Kalimantan & $\begin{array}{l}\text { the Indonesian name for Borneo: applied to the Indonesian } \\
\text { part of the island } \\
\text { only, excluding the Malaysian states of Sabah and Sarawak } \\
\text { and the sultanate of Brunei. Pop: } 11341558(2000)\end{array}$ & Geografi \\
\hline 26. & Maluku & the Indonesian name for the Moluccas & Geografi \\
\hline 27. & Jawa & Indonesian name for Indonesian Java & Linguistik \\
\hline 28. & Malang & $\begin{array}{l}\text { a city in S Indonesia, on E Java: commercial centre. Pop: } \\
756982(2000)\end{array}$ & Geografi \\
\hline 29. & Nusa Tenggara & $\begin{array}{l}\text { an island chain east of Java, mostly in Indonesia: the main } \\
\text { islands are Bali, Lombok, Sumbawa, Sumba, Flores, Alor, } \\
\text { and Timor. Pop: } \frac{11112702(2000)}{11} \text {. Area: } 73 \frac{144 \mathrm{sq} k m}{140} \\
\text { (28 } 241 \mathrm{sq} \text { miles). English name: Lesser Sunda Islands }\end{array}$ & Geografi \\
\hline 30. & Nipa & $\begin{array}{l}\text { a palm tree, Nipa fruticans, of S and SE Asia, having } \\
\text { feathery leaves, used for thatching, and edible fruit }\end{array}$ & Biologi \\
\hline 31. & Irian & $\begin{array}{l}\text { Indonesian name for Indonesian New } \\
\text { Guinea noun:proper_name }\end{array}$ & Geografi \\
\hline 32. & Aceh & 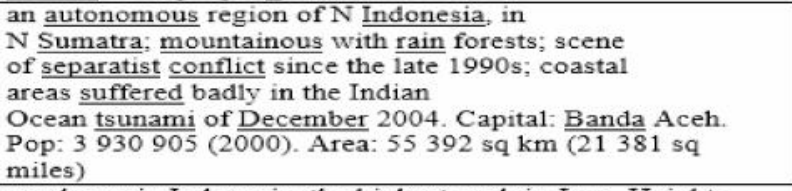 & Geografi \\
\hline 33. & Semeru & 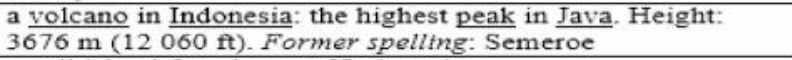 & Geografi \\
\hline 34. & Krakatau & $\begin{array}{l}\text { small island \& volcano of Indonesia, } \\
\text { between Java \& Sumatra: } 2,667 \mathrm{ft}(813 \mathrm{~m}) \text { : also Kraka toa }\end{array}$ & Geografi \\
\hline 35. & Soekarno & a variant spelling of (Achmed) Sukarno & Linguistik \\
\hline 36. & Sukarno & $\begin{array}{l}\text { Achmed ( a:kmed). } 1901- \\
70, \text { Indonesian statesman; first president of } \\
\text { the Republic of Indonesia (1945-67) }\end{array}$ & Tokoh \\
\hline 37. & Sumbawa & $\begin{array}{l}\text { a mountainous island in Indonesia, in the Lesser Sunda } \\
\text { Islands, between Lombok and Flores islands. Pop: } 1540000 \\
(2000) \text {. Area: } 14 \text { 750 sq } \mathrm{km} \text { ( } 5695 \mathrm{sq} \text { miles). Former } \\
\text { spelling: Soembawa }\end{array}$ & Geografi \\
\hline 38. & Padang2 & $\begin{array}{l}\text { A seaport in W central Sumatra, in W Indonesia. } 143.699 \\
(1961)\end{array}$ & Geografi \\
\hline 39. & Bamboo & $\begin{array}{l}\text { A tall tropical plant of the grass family or its hard, hollow, } \\
\text { jointed, stems, which are used e.g. for making furniture }\end{array}$ & Biologi \\
\hline 40. & Suharto & $\begin{array}{l}\text { An army general who became president of Indonesia in } \\
1967\end{array}$ & Tokoh \\
\hline 41. & Sumbawa & $\begin{array}{l}\text { One of the lesser Sunda Islands in Indonesia; destructive } \\
\text { eruption in } 1815 \text { of MT Tambora. 194,819 (est. 1961);5965 } \\
\text { sq. mi. Dutch Soembawa }\end{array}$ & Geografi \\
\hline
\end{tabular}


Secara umum kata asal Indonesia yang diserap adalah kata yang berhubungan dengan geografi dimana nama kota dan nama pulau mendominasi. Sisanya nama makanan, benda, binatang langka, dan nama tokoh. Frasa ilustrasi yang disajikan dalam kamus menjadi pertanda bahwa kata-kata yang diperoleh telah benar-benar diserap ke dalam korpus Bahasa Inggris. Frasa ilustratif mencakup definisi, data geografis, dan demografis.

Serapan kosakata dalam
bahasa Indonesia lebih banyak ditemukan dalam kamus online dibanding kamus cetak. Selain itu frasa ilustratif dalam kamus online menjelaskan kata yang diserap tersebut dengan lebih jelas, padahal analisis offline pada kamus cetak yang dilakukan telah maksimal. Hal ini terjadi kamus online yang bisa diperbaharui melalui system informasi computer sedangkan versi cetak harus menunggu edisi terbaru yang memakan waktu hingga bertahun-tahun. 'Dari Tabel di atas dapat disimpulkan bahwa "batik" menjadi kata serapan asal Indonesia yang paling sempurna diserap ke dalam kamus Bahasa Inggris. "Batik" diserap menjadi kata Kerja, kata sifat, dan kata benda. Kata serapan berikutnya, "Padang" bermakna bermakna "lapangan" selain nama Pelabuhan.

Wajar saja bila definisi yang diberikan para pembuat kamus tidak sesuai yang kita harapkan dan kita ketahui sebagai orang Indonesia karena lexicographer (Pembuat kamus) tentunya memiliki keterbatasan informasi tentang kata yang diserap tersebut. Dapat diambil contoh, "Nama kot"a versus "Nama Pelabuhan", kita sebagai warga Indonesia tahu betul bahwa Surabaya adalah kota kedua terbesar di Indonesia setelah Jakarta. Apa boleh buat, pemuat kamus justru mengilustrasikan Surabaya sebagai nama pelabuhan. Ini juga terjadi pada kata Padang, Jambi, Bandar lampung, Palembang, dan Semarang. Yang menarik Justru “Aceh" yang didefinisikan sebagai wilayah di Indonesia yang pernah mengalami konflik. Nama tokoh penting Indonesia juga mendapat tempat di Korpus bahasa Inggris. Adalah Soekarno (Sukarno). dan Suharto yang menjadi entri dalam kamus bahasa Inggris. Soekarno 
diilustrasikan sebagai Presiden Indonesia yang pertama. Suharto sendiri diilustrasikan sebagai Jendral yang menjadi Presiden Indonesia tahun 1967.

Untuk makanan popular seperti Sate, juga mendapat tempat. Sayang, "rendang" belum diserap ke dalam korpus bahasa Inggris. Semoga di edisi berikutnya sudah diserap, mengingat Rendang pernah dinobatkan sebagai makanan terenak di dunia versi salah satu survey penerbangan. Dengan membawa parameter kepopuleran, "Komodo" dan "Krakatau" justru mendapat tempat di Korpus bahasa Inggris. Komodo didefinisikan sebagai kadal terbesar yang masih hidup dan juga sebagai nama pulau di gugusan Sunda. Krakatau diilustrasikan sebagai Gunung berapi aktif di selat Sunda. Kita ingat kembali bahwa Letusan gunung Krakatau telah di filmkan oleh seorang sutradara asla luar negeri dan filmnya sudah mendunia. Kemudian Komodo adalah hewan langka yang banyak diperbincangkan di seluruh dunia.

\section{Kesimpulan}

1. Terdapat 41 entri yang berasal dari Bahasa Indonesia yang diserap ke dalam Korpus Bahasa Inggris disertai frasa ilustratif.

2. Frasa ilustratif kata serapan Bahasa Indonesia dalam Korpus Bahasa Inggris di dominasi elemen geografis. Sisanya dari bidang Biologi, kuliner, dan Tokoh sejarah.

3. Posisi Bahasa Indonesia dalam Korpus Bahasa Inggris masih sangat kecil. Hanya 41 dari jutaan entri di sana.

4. Pengembangan Korpus Bahasa Indonesia harus lebih selektif dalam menyerap istilah asing, melihat dalam Korpus Bahasa Inggris hal yang sama diterapkan.

\section{Daftar Pustaka}

Atkins, B. and Rundell, M. 2008. The Oxford Guide to Practical Lexicography. London: Oxford University Press.

Himmelman, Nikolaus. 2009. Lingusitic Data Type and Documentary Linguistics. Westfalische: WilhelmsUniversitan Munster.

Miles, M.B. and Huberman, A.M. 1994. Qualitative Data Analysis.CA: Thousand Oaks.

_. 1993. Longman Dictionary of English Language and Culture, Burnt Mill, Harlow, Essex

CM20 2JE, England https://www.collinsdictionary.com/, diakses November 2016 